\title{
Use of Near-Real-Time Data to Inform Underage Drinking Surveillance in Nebraska
}

\author{
Sandra Gonzalez ${ }^{\star 1,3}$, David DeVries ${ }^{2}$ and Ming $\mathbf{Q u}^{3}$ \\ 'University of Nebraska-Lincoln, Lincoln, NE, USA; ${ }^{2}$ Division of Behavioral Health, Nebraska Department of Health and Human \\ Services, Lincoln, NE, USA; ${ }^{3}$ Division of Public Health, Nebraska Department of Health and Human Services, Lincoln, NE, USA
}

\section{Objective}

The objective of this pilot study was to develop and evaluate syndromic definitions for the monitoring of alcohol-related emergency department (ED) visits in near-real-time syndromic surveillance (SyS) data. This study also evaluates the utility of SyS ED data for the monitoring of underage drinking.

\section{Introduction}

Underage drinking is a significant public health problem in the United States as well as in Nebraska ${ }^{1-2}$. Alcohol consumption among underage youth accounts for approximately 5,000 deaths each year in the United States, including motor vehicle crash related deaths, homicides and suicides ${ }^{1}$. In Nebraska, $23 \%$ of $12-20$ year olds have reported alcohol use during the past 30 days $^{3}$. In 2010, the estimated total costs of underage drinking in Nebraska were $\$ 423$ million. These costs included medical care, work loss along with pain and suffering ${ }^{2}$. The health consequences of underage drinking include alcohol-related motor vehicle crashes and other unintentional injuries, physical and sexual assault, suicide, self-inflicted injury, death from alcohol poisoning, and abuse of other drugs ${ }^{1,4}$. The monitoring of near-real-time ED data could help underage drinking prevention efforts by providing timelier actionable public health information.

\section{Methods}

Nebraska SyS data from 32 ED facilities was analyzed for visits of 12 to 20 year olds during October 1, 2015 to August 31, 2016. Three syndromic definitions were developed and tested for the monitoring of alcohol-related ED visits in near-real-time SyS data by using ESSENCE. The first and second definitions were based on querying the chief complaint (CC) field for search terms associated with alcohol use and alcohol abuse or intoxication respectively. The third definition consisted of ICD-9-CM and ICD-10-CM diagnostic codes associated to alcohol abuse or intoxication. These three definitions were evaluated for internal consistency: reported diagnostic codes were used to evaluate the first and second definition, while text in the CC field was used to evaluate the third definition. Records with missing CC or diagnostic codes were excluded from the consistency analysis. In addition, the $\mathrm{CC}$ field of records detected by the third definition was evaluated for possible alcohol-related health consequences.

\section{Results}

A total of 126 cases were detected by using the first definition (CC search terms for alcohol use); 61\% (50/82) of these identified alcohol abuse-related diagnostic codes. On the other hand, a total of 64 cases were detected by using second definition (CC search terms specific for alcohol abuse or intoxication); 89\% (33/37) of these identified alcohol abuse-related diagnostic codes. The third definition (diagnostic codes only) detected 111 cases; 49\% (51/105) of these identified alcohol-related search terms in records with reported CC. However, keywords associated to alcohol-related health consequences, such as injury, assault, and use of other drugs were found in records with no alcohol-related search terms in the CC field. Diagnostic codes associated to alcohol-related health consequences were observed in $93 \%(50 / 54)$ of these records. These results indicate that alcohol use is underreported in the CC field.

\section{Conclusions}

A higher internal consistency was observed for the syndromic definition based on CC search terms associated with alcohol abuse or intoxication. However, a syndromic definition based on diagnostic codes is preferred due to the underreporting of alcohol use in the CC field. The detection of underage alcohol use-related cases could be improved by adding alcohol abuse or intoxication CC search terms to a syndromic definition based on diagnostic codes. Overall, results of this pilot study suggest that a syndromic definition based on diagnostic codes can potentially enhance the surveillance of underage drinking and alcohol-related health consequences.

\section{Keywords}

Syndromic Surveillance; Underage Drinking; Emergency Department; Alcohol; Injury

\section{Acknowledgments}

Other contributors: Bryan Buss, Gary White, Lianlin Zhao, David Loyall, Kevin Cueto, and Michelle Hood

\section{References}

1. Hingson R, White A. New research findings since the 2007 Surgeon General's Call to Action to Prevent and Reduce Underage Drinking: a review. J Stud Alcohol Drugs. 2014 Jan;75(1):158-69. Review.

2. Bekmuratova S, Carritt N, Kaldahl T, Stimpson JP. Underage Drinking in Nebraska [Internet]. Omaha (NE): University of Nebraska Medical Center, Center for Health Policy; 2013 August [cited 2016 September 7]. Available from: https://www.unmc.edu/publichealth/ chp/research/2013-underage-drinking.pdf.

3. U.S. Department of Health and Human Services. The December 2015 Report to Congress on the Prevention and Reduction of Underage Drinking [Internet]. 2015 [cited 2016 September 7]. Available from: https://www.stopalcoholabuse.gov/media/ReportToCongress/2015/ state_reports/nebraska_profile.pdf.

4. CDC. Fact Sheets - Underage Drinking [Internet]. 2015 November [cited 2016 September 7]. Available from: http://www.cdc.gov/ alcohol/fact-sheets/underage-drinking.htm.

\section{*Sandra Gonzalez}

E-mail: Sandra.Gonzalez@nebraska.gov 